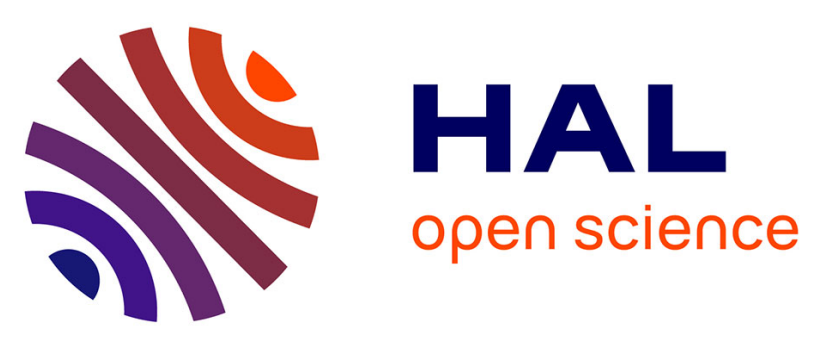

\title{
Hydrodeoxygenation of benzyl alcohol on transition-metal-containing mixed oxides catalysts derived from layered double hydroxide precursors
}

Claudiu Rizescu, Chao Sun, Ionel Popescu, Adriana Urdă, Patrick da Costa, Ioan-Cezar Marcu

\section{To cite this version:}

Claudiu Rizescu, Chao Sun, Ionel Popescu, Adriana Urdă, Patrick da Costa, et al.. Hydrodeoxygenation of benzyl alcohol on transition-metal-containing mixed oxides catalysts derived from layered double hydroxide precursors. Catalysis Today, 2021, 366, pp.235-244. 10.1016/j.cattod.2020.04.055 . hal-03169517

\section{HAL Id: hal-03169517 \\ https: / hal.sorbonne-universite.fr/hal-03169517}

Submitted on 15 Mar 2021

HAL is a multi-disciplinary open access archive for the deposit and dissemination of scientific research documents, whether they are published or not. The documents may come from teaching and research institutions in France or abroad, or from public or private research centers.
L'archive ouverte pluridisciplinaire HAL, est destinée au dépôt et à la diffusion de documents scientifiques de niveau recherche, publiés ou non, émanant des établissements d'enseignement et de recherche français ou étrangers, des laboratoires publics ou privés. 


\title{
Catalysis Today, volume 366, 2021, pp 235-244
}

\author{
https://doi.org/10.1016/j.cattod.2020.04.055
}

\author{
Hydrodeoxygenation of benzyl alcohol on transition-metal-containing mixed \\ oxides catalysts derived from layered double hydroxide precursors
}

Claudiu Rizescu a, Chao Sun b, Ionel Popescu c, Adriana Urda a,c, ${ }^{*}$, Patrick Da Costa b, loan-Cezar Marcu a,c, ${ }^{*}$

a Laboratory of Chemical Technology and Catalysis, Department of Organic Chemistry, Biochemistry and Catalysis, Faculty of Chemistry, University of Bucharest, 4-12, Blvd. Regina Elisabeta, 030018 Bucharest, Romania b Equipe Combustion, Energie Propre et Turbulence, Institut Jean Le Rond d'Alembert, Sorbonne Universit' e, CNRS UMR 7190, 2, Place de la Gare de Ceinture, 78210 Saint Cyr L'Ecole, France c Research Center for Catalysts and Catalytic Processes, Faculty of Chemistry, University of Bucharest, 4-12, Blvd. Regina Elisabeta, 030018 Bucharest, Romania

* Corresponding authors at: Laboratory of Chemical Technology and Catalysis, Department of Organic Chemistry, Biochemistry and Catalysis, Faculty of Chemistry, University of Bucharest, 4-12, Blvd. Regina Elisabeta, 030018 Bucharest, Romania. E-mail addresses: adriana.urda@chimie.unibuc.ro (A. Urdā), ioancezar.marcu@chimie.unibuc.ro (I.-C. Marcu).

https://doi.org/10.1016/j.cattod.2020.04.055

Abstract: M-MgAlO mixed oxide catalysts were prepared by controlled thermal decomposition of layered double hydroxides (LDH) precursors and were tested in the hydrodeoxygenation of benzyl alcohol. LDH with $\mathrm{Mg} / \mathrm{Al}=3$ and 10 at. $\% \mathrm{M}$ with respect to cations $(\mathrm{M}=\mathrm{Mn}, \mathrm{Fe}, \mathrm{Co}, \mathrm{Ni}, \mathrm{Cu}$ and $\mathrm{Zn})$ were obtained by coprecipitation. A second series of copper-containing catalysts with copper content from 5 to 20 at. \% was also prepared. The solids were characterized by X-ray diffraction, N2 adsorption/desorption, temperatureprogrammed reduction in $\mathrm{H} 2$ atmosphere, temperature-programmed desorption of $\mathrm{CO} 2$. The influence of the transition metal and, for the copper-containing samples, of the copper loading, reaction temperature, reaction time, amount of catalyst and reduction pre-treatment on the catalytic performance were investigated. With $97 \%$ alcohol conversion and $96 \%$ selectivity to toluene, Cu15MgAlO is the best hydrodeoxygenation catalyst. It was also tested in the hydrodeoxygenation of 1-heptanol. 
Keywords: Transition-metal Copper LDH Catalytic hydrodeoxygenation Benzyl alcohol

\section{Introduction}

Alternatives for the replacement of conventional fossil fuels or of oil sources for hydrocarbons are intensively researched in order to find sustainable solutions compatible with the current infrastructure, being able to decrease $\mathrm{CO} 2$ emissions and environmental energy footprint [1-3]. Biomass obtained from plants, and also from non-edible lignocellulosic materials that can be produced on large scale within a relatively short time, can become a renewable source for both energy and chemicals $[4,5]$. The production of fuels and chemicals by upgrading of lignin, a substituted phenolic polymer component of lignocellulose, remains a significant challenge. Depolymerization of lignin into oligomeric and monomeric substituted phenols $[2,5]$ and flash pyrolysis leading to the so-called bio-oil [1] are two intensely studied processes for the valorization of lignin. The oxygen-containing fractions that are obtained need to be upgraded by hydrodeoxygenation in order to be used as fuels or as a source for petroleum-like hydrocarbons [4-7]. The high oxygen content of the depolymerization products leads to low heating value, high viscosity, chemical instability and low $\mathrm{pH}(\sim 2.5)$, resulting in poor operational characteristics $[4,6,7]$. Hydrodeoxygenation (HDO) reaction converts the oxygen-containing compounds to hydrocarbons by treating them at medium temperatures $\left(200-400{ }^{\circ} \mathrm{C}\right.$ ) and pressures (up to 200 bars) via hydrogenolysis of the $\mathrm{C}-\mathrm{O}$ bonds $[8,9]$. Concomitant hydrogenation reactions are not desirable, since for the production of biomass-derived chemicals the preservation of some functional groups in the molecules is required [10], e.g. the aromatic ring in the HDO of benzyl alcohol. Active catalysts for HDO are desired to be bifunctional, with an acid (either 
Lewis or Brønsted) or an oxide of a transition metal with variable valence for the activation of oxy-groups, together with a transition metal in a reduced state to activate the hydrogen molecule $[4,5]$. The removal of oxygenated moieties requires the two catalytic functions to work either independently or cooperatively [5]. Noble metals such as Pd, Pt and Ru are known for their hydrogen activation function, and were used for HDO of phenolic bio-oil components such as phenols, guaiacols, syringols [5-7,9-13] and benzaldehyde [14,15]. Some studies used catalysts combining noble and transition metals, such as supported RhCo in the HDO of anisole and biodiesel [4] or Ru-Fe in supported ionic liquid phase catalysts in HDO of aromatic substrates containing carbonyl groups [16]. However, noble metals are expensive, and hence their replacement by other transition metals is desired $[4,8]$ and was thoroughly investigated $[3,8,10,17-24]$. Another beneficial effect of transition-metal catalysts is that complete hydrogenation of the oxygenated compounds is avoided $[3,10]$. For example, Ni-based catalysts (37-58 \% Ni) modified with copper (2-10\% Cu) to facilitate the reduction of $\mathrm{NiO}$ at low temperature and stabilized with oxides such as $\mathrm{Al} 2 \mathrm{O} 3, \mathrm{SiO} 2$, $\mathrm{CeO} 2-\mathrm{ZrO} 2$, were tested in the HDO of guaiacol [8]. High conversions were obtained for all catalysts (80-97 \%) with selectivities to HDO up to $97 \%$. Other tested catalysts were molybdenum nitrides [17], Mo2C [22], copper chromite [3], Ni-Fe/SiO2 [19], Ni-Fe/ $\mathrm{Y}-\mathrm{Al} 2 \mathrm{O} 3$ [18], Ni-Mo/ $/$-Al2O3 [24], NiFe alloys [21], supported Ni catalysts [20,23]. Mixed oxides catalysts containing copper are interesting for HDO reactions due to their high activity in hydrogenolysis and low tendency towards complete hydrogenation of the substrates [3]. Catalysts with finely dispersed copper were studied in catalytic conversion of alcohols $[25,26]$. Since bulk copper is catalytically inactive [27], supports are needed for a high dispersion and to avoid the sintering of copper particles [26]. Some of the supports discussed in the literature possess surface acidity that promotes undesired side reactions of 
alcohols, such as dehydration. Therefore, basic solids such as hydrotalcites or mixed oxides obtained by their thermal decomposition have been used as supports for the catalytic conversion of alcohols [26] due to the synergy between the basic support and the hydrogen spill over copper. Due to complexity in testing real mixtures of compounds obtained from biomass, the study of hydrodeoxygenation is usually focused on model species possessing a hydroxyl group that is an abundant functional group in biomass [10], such as phenol, guaiacol, anisole etc. $[3,8,28]$. Benzyl alcohol is one of these model compounds, but much less studied than other platform molecules. The HDO of benzyl alcohol was investigated using homogeneous catalysts, such as $\mathrm{Ni}$ - and Pd-terpyridine complexes [2], tetrabutylammonium molybdate [10], or heterogeneous catalytic materials, such as copper chromite [3], Pt or Pd deposited on Al2O3 [15,29,30]. Noble metals (Pt, Pd) were active in gas phase HDO, but deactivated due to carbon deposition on their surface [15]. This contribution presents the study of benzyl alcohol HDO over M-MgAlO mixed oxide catalysts ( $\mathrm{M}=\mathrm{Mn}, \mathrm{Fe}, \mathrm{Co}, \mathrm{Ni}, \mathrm{Cu}, \mathrm{Zn}$ ) prepared by controlled thermal decomposition of layered double hydroxide (LDH) precursors. Different parameters were investigated, such as the nature of the transition metals - $\mathrm{Mn}, \mathrm{Fe}, \mathrm{Co}, \mathrm{Ni}, \mathrm{Cu}, \mathrm{Zn}$; and for $\mathrm{Cu}$-containing catalysts, the reaction temperature, reaction time, copper loading and reduction pre-treatment, in order to find the optimum process conditions.

\section{Experimental}

\subsection{Catalyst preparation}

The $\mathrm{M}-\mathrm{MgAl}-\mathrm{LDH}$ precursors $(\mathrm{M}=\mathrm{Mn}, \mathrm{Fe}, \mathrm{Co}, \mathrm{Ni}, \mathrm{Cu}$ and $\mathrm{Zn}$ ) with $\mathrm{Mg} / \mathrm{Al}=3$ and 10 at. $\% \mathrm{M}$ with respect to cations or, for $\mathrm{M}=\mathrm{Cu}$, in the range from 5 to 20 at. \%, were prepared by co- 
precipitation with a $2 \mathrm{M}$ solution of $\mathrm{NaOH}$ at constant $\mathrm{pH}$ of 10 , followed by washing, separation by centrifugation and drying at $80 \circ \mathrm{C}$ [31]. The corresponding mixed oxides were obtained by calcination at $500{ }^{\circ} \mathrm{C}$ for $5 \mathrm{~h}$. All the prepared mixed oxides with 10 at. \% metal were named M-MgAlO, while the Cu-containing samples were labeled CuxMgAlO, where $x$ is the $\mathrm{Cu}$ content.

\subsection{Catalysts characterization}

The structure and phase composition of the catalysts were examined by X-ray diffraction experiment performed on a PANalytical-Empyrean diffractometer, equipped with CuK $\alpha$ of $\lambda$ $=0.15406 \mathrm{~nm}$ radiation source. The average crystallite size of copper species was calculated from the Scherrer equation. The textural properties of the catalysts were determined from their corresponding N2 adsorption isotherms obtained during low temperature N2 sorption experiments carried out on Belsorp Mini II apparatus from BEL Japan. Prior to each measurement, mixed-oxide powders were degassed under vacuum for $2 \mathrm{~h}$ at $300{ }^{\circ} \mathrm{C}$. The reducibility of calcined samples was determined by temperature-programmed reduction (H2-TPR) measurements which were carried out in a BEL Japan BELCAT-M, equipped with a TCD detector. $60 \mathrm{mg}$ of each catalyst was first degassed in pure helium (flow rate: $50 \mathrm{~mL}$ $/ \mathrm{min}$ ) at $450{ }^{\circ} \mathrm{C}$ for $1 \mathrm{~h}$. After cooling down to $80{ }^{\circ} \mathrm{C}$ under $\mathrm{He}$, the sample was reduced with $5 \% \mathrm{H} 2 / \operatorname{Ar}$ mixture $(50 \mathrm{~mL} / \mathrm{min})$ in the temperature range from $80{ }^{\circ} \mathrm{C}$ to $500 \circ \mathrm{C}$ with a heating rate of $10{ }^{\circ} \mathrm{C} / \mathrm{min}$. The basic properties of samples were examined by temperature programmed desorption of carbon dioxide. The CO2-TPD measurement was performed just after the H2-TPR measurement, using the same apparatus. CO2 was adsorbed on the sample from a mixture of $10 \% \mathrm{CO} 2$ in $\mathrm{He}(50 \mathrm{~mL} / \mathrm{min})$. Subsequently, the weakly physically adsorbed carbon dioxide was desorbed in a flow of pure He (50 mL / min) for $15 \mathrm{~min}$. Finally, 
the samples were heated from $80{ }^{\circ} \mathrm{C}$ to $500{ }^{\circ} \mathrm{C}$ in helium (50 $\mathrm{mL} / \mathrm{min}$ ) with a ramp of 10 ${ }^{\circ} \mathrm{C} / \mathrm{min}$.

\subsection{Catalytic tests}

Catalytic tests were performed in a $16 \mathrm{ml}$ magnetically stirred stainless steel autoclave reactor (HEL Limited) at $230{ }^{\circ} \mathrm{C}$, under initial hydrogen pressure of $5 \mathrm{~atm}$, with $1 \mathrm{ml}$ of benzyl alcohol and, if not otherwise specified, $50 \mathrm{mg}$ of catalyst. For the Cu-containing catalysts, the effects of the reaction temperature in the range from 150 to $230{ }^{\circ} \mathrm{C}$, $\mathrm{Cu}$ loading $(5-20$ at. $\%)$, the reaction time $(0.5-5 \mathrm{~h})$ and the catalyst weight $(25-100 \mathrm{mg})$ were investigated. Blank tests (without catalyst) showed very small conversion values for benzyl alcohol (ca. 1 \%). After cooling to room temperature, the gaseous reaction products were collected and analyzed on a Trace GC chromatograph (CE Instruments) equipped with a TCD detector and a Carboxen column. The liquid products were extracted with isopropyl alcohol from the suspension containing the spent catalyst, separated by centrifugation, then the extract was analyzed on a Trace GC chromatograph (ThermoFinnigan) equipped with a FID detector and a DB-5 column. In all catalytic tests, the gaseous reaction products consisted of hydrogen and traces of carbon oxides and methane. The liquid products were composed mainly of toluene, benzaldehyde, benzyl benzoate, benzene and in some cases cyclohexane as HDO reaction products, and unconverted benzyl alcohol. Conversion was calculated as the amount of benzyl alcohol converted into products divided by the amount of alcohol introduced in the reaction. Selectivity was calculated as the amount of alcohol transformed into product divided by the amount of alcohol that was transformed.

\section{Results and discussion}




\subsection{Catalysts characterization}

The XRD patterns of the M-MgAl-LDH precursors are displayed in Fig. 1a. MgAl-LDH exhibited the typical XRD pattern of the LDH structure (JCPDS 37-0630) with intense and narrow diffraction lines below $30^{\circ} \_2 \theta$, ascribed to (003) and (006) planes. Wide and asymmetric reflections particularly in the $30-50 \circ \_2 \theta$ _range were obtained, as usually observed.
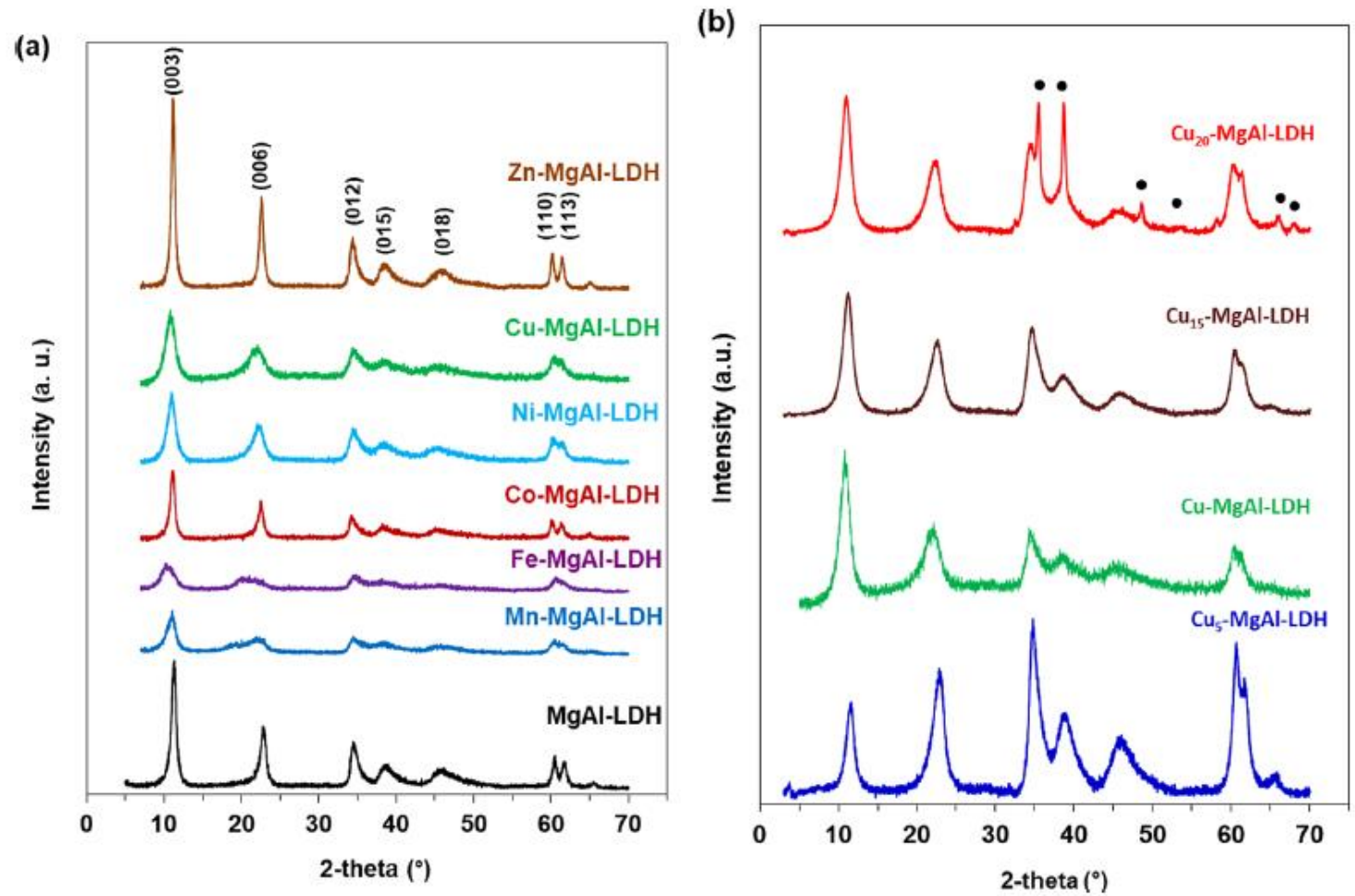

Fig. 1. The XRD patterns of the (a) MgAl-LDH, M-MgAl-LDH and (b) Cux-MgAl-LDH ( $x=5,10,15$ and 20) precursors; • segregated CuO phase.

The reflections corresponded to a hexagonal lattice with $\mathrm{R} 3 \mathrm{~m} 0.306 \mathrm{~nm}$. They were calculated from the position of the (003) $(c=3$. d003) and (110) $(a=2$. d110) reflections, respectively. All the M-MgAl-LDH precursors exhibited similar XRD patterns, with less crystallized structures for Fe-MgAl-LDH and Mn-MgAl-LDH. This could be related to the large ionic size and/or the partial oxidation of the transition metal cation, as already observed for 
Fe- and Mn-containing LDH structures [32]. In all the M-MgAl-LDH samples the cell parameter $a$ is close to that of $\operatorname{MgAl-LDH}(a=0.306 \pm 0.001 \mathrm{~nm})$ showing no variation of the mean intermetallic distances in the brucite-like layers (Table 1). This result is in agreement with the low content of $M$ cations, therefore only slightly modifying the intermetallic distances in the brucite-like layers. The value of c parameter, which depends on several factors, such as the average charge of the layers, the nature of the interlayer anion and the water content, is in line with the presence of nitrates as compensating anions provided by the precursor salts [33]. The LDH diffractograms of the CuxMgAl-LDH precursors $(x=5,10$, 15, 20 at. \%) show the same typical patterns for the LDH structure (Fig. 1b). The sample with 20 at. \% $\mathrm{Cu}$ shows additional diffraction lines attributed to a segregated CuO phase (JPCDS 07-0518). This is a common feature of the Cu-containing MgAl-LDH materials with high $\mathrm{Cu}$ content [34,35]. The average crystallite size in the c direction (the stacking direction perpendicular to the layers) was estimated from the (003) reflection by means of DebyeScherrer equation:

$$
D \approx \frac{1.08 \lambda}{(2 \theta)_{F W H M} \cos \theta}
$$

where $D$ is the particle size, $\lambda_{-}$is the wavelength of the $\mathrm{Cu} K \alpha$ _radiation $(0.15418 \mathrm{~nm}), \vartheta$ is the Bragg diffraction angle and FWHM is the full width at half-maximum of the LDH (003) reflection. The crystallite size of the LDH precursors ranges between $5.6 \mathrm{~nm}$ for Fe-MgAlLDH and $18.4 \mathrm{~nm}$ for Zn-MgAl-LDH (Table 1), for most of them being lower than $10 \mathrm{~nm}$. For the Cux-MgAl-LDH samples the crystallite size decreases with increasing the Cu content. 


\begin{tabular}{|c|c|c|c|}
\hline \multirow{2}{*}{ Sample } & \multicolumn{2}{|c|}{ Unit cell parameters (nm) } & \multirow{2}{*}{ Crystallite size $(\mathrm{nm})$} \\
\hline & $a$ & $c$ & \\
\hline MgAl-LDH & 0.306 & 2.354 & 13.8 \\
\hline Mn-MgAl-LDH & 0.306 & 2.431 & 8.0 \\
\hline Fe-MgAl-LDH & 0.305 & 2.535 & 5.6 \\
\hline Co-MgAl-LDH & 0.307 & 2.392 & 14.5 \\
\hline Ni-MgAl-LDH & 0.306 & 2.423 & 8.3 \\
\hline Cu-MgAl-LDH & 0.306 & 2.451 & 7.2 \\
\hline Zn-MgAl-LDH & 0.307 & 2.374 & 18.4 \\
\hline $\mathrm{Cu}_{3} \mathrm{MgAl}-\mathrm{LDH}$ & 0.305 & 2.289 & 7.8 \\
\hline $\mathrm{Cu}_{1}$ g MgAl-LDH & 0.306 & 2.354 & 6.5 \\
\hline $\mathrm{Cu}_{20} \mathrm{MgAl}-\mathrm{LDH}$ & 0.307 & 2.418 & 6.4 \\
\hline
\end{tabular}

a Value of crystallite size in $c$ direction calculated from Debye-Scherrer equation using the FWHM of (003) reflection.

All the M-MgAlO and CuxMgAlO samples calcined at $500{ }^{\circ} \mathrm{C}$ exhibited the same diffraction lines as the transition-metal-free MgAlO mixed oxide at ca. 43 and $63^{\circ} 2 \theta$ (Fig. 2), which correspond to the (200) and (220) reflections of the $\mathrm{Mg}(\mathrm{Al}) \mathrm{O}$ periclase-like structure (JCPDSICDD4- 0829). Except for the CuxMgAlO samples, no segregated transition-metal-containing phases were detected in the M-MgAlO mixed oxides, suggesting that the transition metal cations are well dispersed in the $\mathrm{Mg}(\mathrm{Al}) \mathrm{O}$ mixed oxide matrix. This was confirmed by the close values of cell parameter $a$ calculated from the position of (200) lines reported in Table 2. However, the presence of low amounts of poorly crystallized transition metal oxide phases cannot be completely ruled out. The CuxMgAlO samples (Fig. 2b) showed additional diffraction lines whose intensity increases with the copper content, that are unambiguously attributed to a segregated CuO phase (JPCDS 07-0518).

Table 2 Physico-chemical characteristics of the mixed oxide catalysts.

\begin{tabular}{|c|c|c|c|c|c|c|}
\hline Catalyst & Transition metal content (at. \%) & $\mathrm{Mg} / \mathrm{Al} \mathrm{mol} \mathrm{ratio}$ & Specific surface area $\left(\mathrm{m}^{2} \mathrm{~g}^{-1}\right)$ & Pore size $(\mathrm{nm})$ & Cell parameter $(\mathrm{nm})$ & Particle size $(\mathrm{nm})$ \\
\hline Mgalo & - & 2.9 & 53.6 & 12.2 & 0.4194 & 7.4 \\
\hline Mn-Mgalo & 10.7 & 3.0 & 21.6 & 22.1 and 39.0 & 0.4184 & 5.2 \\
\hline Fe-MgAlO & 10.0 & 3.0 & 22.1 & 22.1 and 39.0 & 0.4196 & 6.0 \\
\hline Cu-MgAlO & 9.1 & 3.0 & 78.6 & 3.8 & 0.4200 & 6.6 \\
\hline Zn-MgAlO & 9.8 & 3.1 & 55.2 & 16.3 & 0.4199 & 7.4 \\
\hline CugMgAlo & 4.6 & 3.0 & 60.4 & 4.6 & 0.4199 & 7.4 \\
\hline
\end{tabular}

The crystallite sizes, calculated by applying the Debye-Scherrer equation to (200) and (220) reflections, are small and close together, ranging between $5.2 \mathrm{~nm}$ for $\mathrm{Mn}-\mathrm{MgAlO}$ and $7.4 \mathrm{~nm}$ 
for MgAlO and Zn-MgAlO (Table 2). Notably, the crystallite size decreases after the thermal treatment of the $\mathrm{LDH}$ precursors at $500{ }^{\circ} \mathrm{C}$. Both the transition metal content and the $\mathrm{Mg} / \mathrm{Al}$ molar ratio, determined by ICP-OES, were shown to be close to the theoretical values (Table 2). The XRD pattern of the Cu15MgAlO spent catalyst, after being dried at $200{ }^{\circ} \mathrm{C}$ for $4 \mathrm{~h}$ in nitrogen flow in order to evaporate the reaction products, is shown in Fig. 3, together with the diffractograms for the fresh sample and the spent catalyst after thermal treatment in air at $500{ }^{\circ} \mathrm{C}$. The spent catalyst showed lines characteristic to a cubic $\mathrm{Cu}_{2} \mathrm{O}$ phase (JCPDS 782076) at $36,43,62$ and $73^{\circ}$, superimposed on the reflections from the poorly crystallized periclase phase at $35,43.5$ and $62^{\circ}$. The reflections at low angles were attributed to a partially reconstructed LDH phase, probably with different interlayered anions from the reaction medium, such as benzoates and benzylates (see discussion in Section 3.2). This partial reconstruction is possible during the catalytic test in hydro/solvothermal conditions. This hypothesis was tested by thermally treating the spent catalyst at $500{ }^{\circ} \mathrm{C}$ in air. Indeed, in the XRD pattern of the recalcined spent sample no reflections at low angles can be observed, but only reflections corresponding to the periclase-like and CUO (JPCDS 07-0518) phases. The textural properties of the M-MgAlO mixed oxides, determined by nitrogen adsorption at $196{ }^{\circ} \mathrm{C}$ are summarized in Table 2 . The specific surface areas are in the range 22-79 $\mathrm{m}^{2} / \mathrm{g}$ for the samples with 10 at. \% transition-metal, while those of CuxMgAlO samples increase with increasing Cu content from 60 to $91 \mathrm{~m}^{2} / \mathrm{g}$. All solids displayed type IV nitrogen adsorption/desorption isotherms according to IUPAC classification, with hysteresis loops characteristic of mesoporous materials [36], as shown in Fig. 4. 


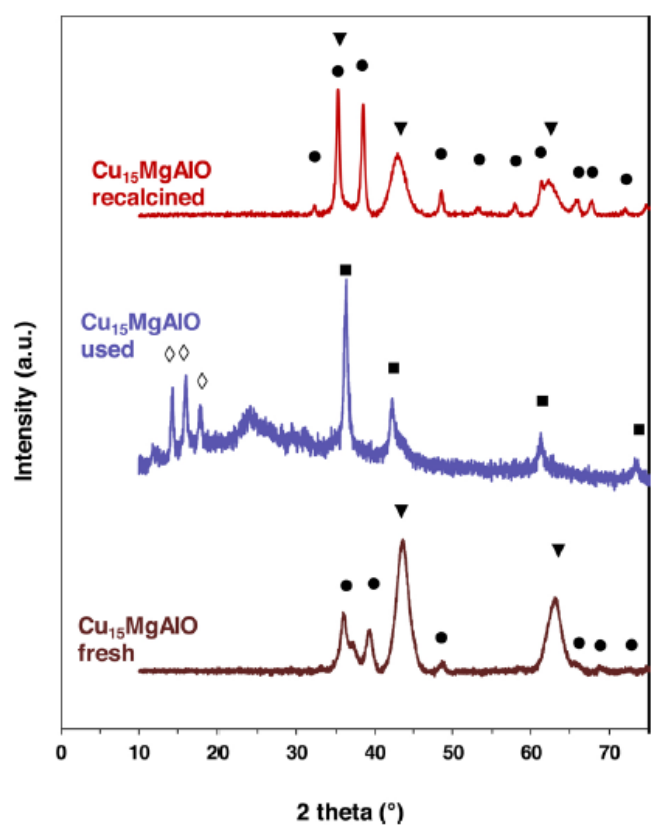

Fig. 3. The XRD pattern of the Cu15MgAlO fresh, spent (after drying at $200{ }^{\circ} \mathrm{C}$ for $4 \mathrm{~h}$ in $\mathrm{N} 2$ flow) and recalcined catalysts; $\checkmark$ - periclase phase; $\diamond$ - reconstructed LDH phases; $\square$ Cu2O phase; $\bullet$ CuO phase.

(a)

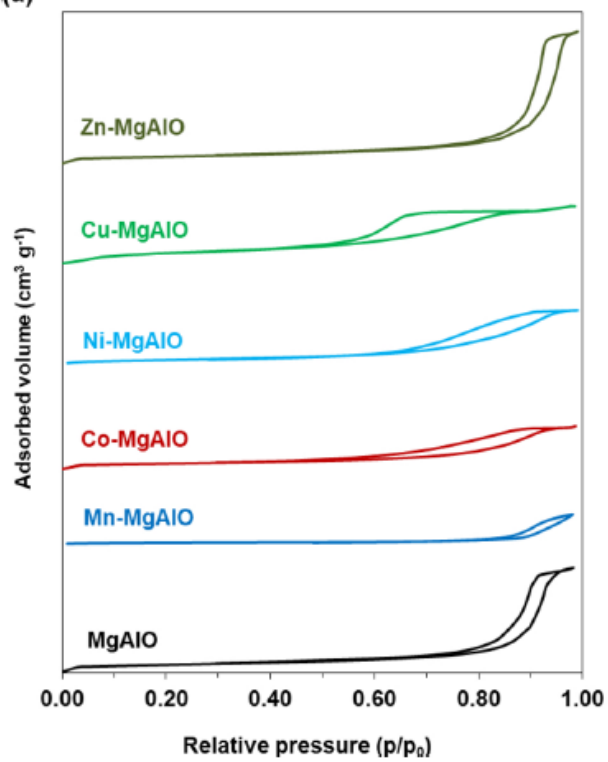

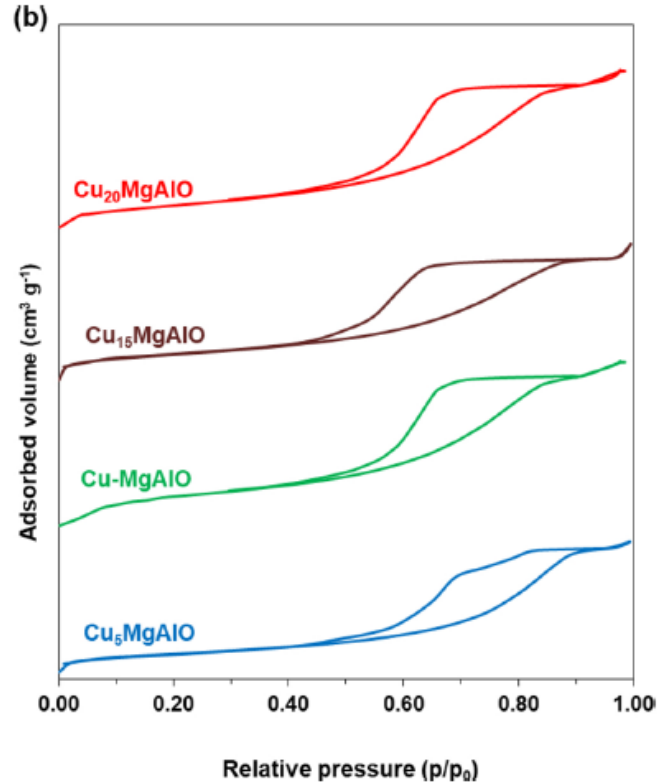

Fig. 4. Nitrogen adsorption/desorption isotherms for the (a) M-MgAlO and (b) CuxMgAlO mixed oxide catalysts.

The M-MgAlO catalysts are expected to have different reducibility due to the different nature of the transition metal cations present in their structure. Therefore temperatureprogrammed reduction profiles in hydrogen atmosphere (H2-TPR) were achieved in order to 
better understand the catalytic behavior of the catalyst samples, and are shown in Fig. 5 . The hydrogen consumption and the corresponding maximum temperatures of the Gaussian curves obtained after deconvolution of the TPR pattern are reported in Table 3. It was checked that the MgAlO sample does not consume any $\mathrm{H}_{2}$.

(a)

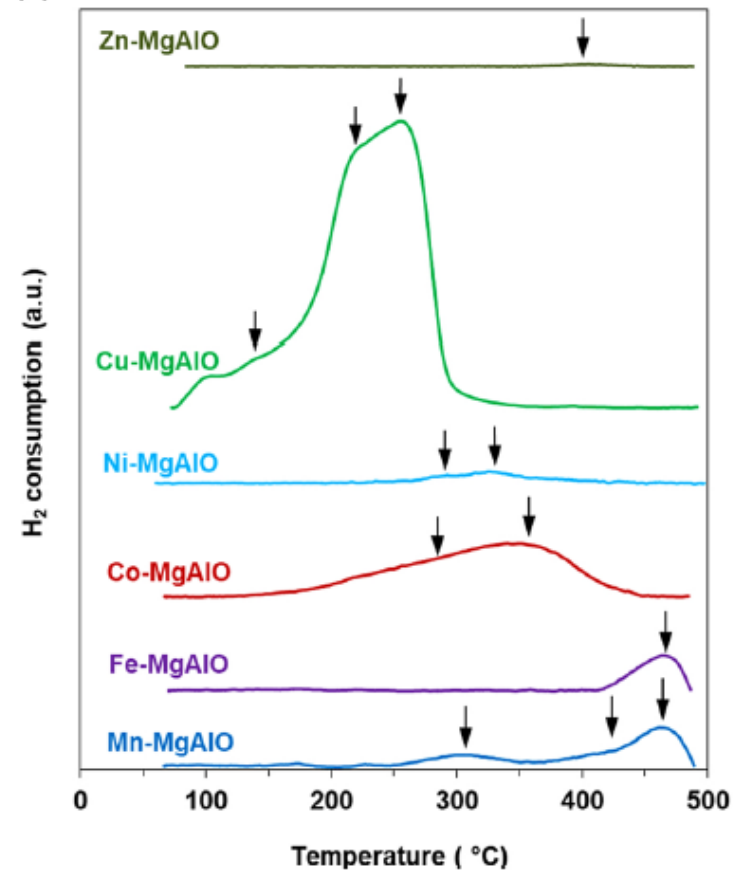

(b)

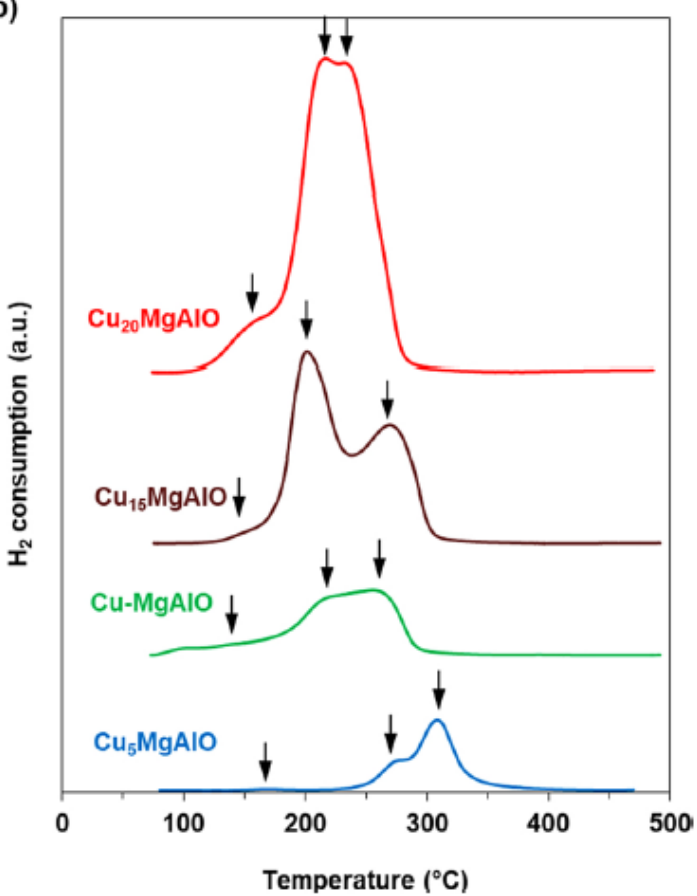

Fig. 5. H2-TPR profiles of the (a) M-MgAlO and (b) CuxMgAlO mixed oxide catalysts.

The peaks observed in the $\mathrm{H}_{2}$-TPR profiles can be assigned to transition-metal oxide particles interacting more or less strongly with the $\mathrm{Mg}(\mathrm{Al}) \mathrm{O}$ matrix. This shows that, although not detected by XRD, except for the CuxMgAlO samples, transition-metal oxide particles are dispersed in the $\mathrm{Mg}(\mathrm{Al}) \mathrm{O}$ matrix. It is worth noting that the hydrogen consumption is rather low for all samples except for the Cu-containing ones. As expected, Zn-MgAlO showed the lowest hydrogen consumption [31], which increases following the order $\mathrm{Zn}-\mathrm{MgAlO}<\mathrm{Ni}-$ MgAlO < Fe-MgAlO < Mn-MgAlO < Co-MgAlO < Cu-MgAlO. On the other hand, for the CuxMgAlO mixed oxides the hydrogen consumption increases with increasing the copper 
content. Also, the high-temperature peak shifts to lower temperatures as the copper content increases (Fig. 5b). This has already been observed and was attributed to the weakening of the axial $\mathrm{Cu}-\mathrm{O}$ bonds as the number of nearest $\mathrm{CuO}$ neighbors increases, likely due to a more pronounced Jahn_Teller tetragonal distortion in the octahedral $\mathrm{Cu} \_\mathrm{O}$ environment [37].

Table $3 \mathrm{H} 2$ consumption and Tmax in H2-TPR of the MMgAlO catalysts.

\begin{tabular}{lll}
\hline Catalyst & $\mathrm{H}_{2}$ consumption $\left(\mu \mathrm{mol} \mathrm{g}^{-1}\right)$ & $\mathrm{T}_{\max }$ \\
\hline Mn-MgAlO & 3.8 & $307 ; 426 ; 464$ \\
Fe-MgAlO & 2.0 & 465 \\
Co-MgAlO & 9.9 & $283 ; 360$ \\
Ni-MgAlO & 1.3 & $290 ; 325$ \\
Cu-MgAlO & 33.5 & $142 ; 229 ; 266$ \\
Zn-MgAlO & 0.2 & 404 \\
$\mathrm{Cu}_{5}$ MgAlO & 18.1 & $175 ; 271 ; 308$ \\
$\mathrm{Cu}_{15}$ MgAlO & 75.5 & $153 ; 204 ; 265$ \\
$\mathrm{Cu}_{20}$ MgAlO & 120.0 & $169 ; 208 ; 238$ \\
\hline
\end{tabular}

The basic properties of the $\mathrm{M}-\mathrm{MgAlO}$ catalysts were investigated by $\mathrm{CO}_{2}-\mathrm{TPD}$, the obtained profiles being presented in Fig. 6. The desorption profiles were deconvoluted in three desorption peaks, corresponding to weak, medium and strong basic sites, respectively [3841]. The weak Brønsted basic sites (temperature maxima in the range $124-133{ }^{\circ} \mathrm{C}$ ) are due to a small number of surface $\mathrm{OH}^{-}$groups that are still present after activation; mediumstrength Lewis sites $\left(169-189{ }^{\circ} \mathrm{C}\right.$ ) are associated with $\mathrm{Mg}^{2-} \mathrm{O}^{2-}$ and $\mathrm{Al}^{3+} \mathrm{O}^{2-}$ acid-base pairs, while strong Lewis basic sites $\left(222-361{ }^{\circ} \mathrm{C}\right)$ are related to low-coordinated $\mathrm{O}^{2-}[42]$.

Table 4 Total number of basic sites and the relative proportions of sites with different strengths for M-MgAlO mixed oxides, determined from TPD of $\mathrm{CO} 2$. 


\begin{tabular}{lllll}
\hline \multirow{2}{*}{ Catalyst } & \multicolumn{2}{l}{ Proportion of } & \multicolumn{2}{l}{$\begin{array}{l}\text { Total number of basic sites } \\
\left(\mu \mathrm{mol} \mathrm{g}^{-1}\right)\end{array}$} \\
\cline { 2 - 4 } & $\begin{array}{l}\text { Weak } \\
(\%)\end{array}$ & $\begin{array}{l}\text { Medium } \\
(\%)\end{array}$ & $\begin{array}{l}\text { Strong } \\
(\%)\end{array}$ & \\
\hline MgAlO & 13.03 & 14.19 & 72.78 & 35.0 \\
Mn-MgAlO & 15.63 & 27.3 & 57.1 & 25.7 \\
Fe-MgAlO & 25.3 & 39.9 & 34.8 & 17.1 \\
Co-MgAlO & 16.2 & 28.8 & 55.0 & 32.9 \\
Ni-MgAlO & 13.3 & 17.0 & 69.7 & 40.5 \\
Cu-MgAlO & 10.2 & 20.6 & 69.2 & 37.2 \\
Zn-MgAlO & 51.5 & 35.7 & 12.8 & 4.4 \\
Cu ${ }_{5}$ MgAlO & 8.7 & 32.8 & 58.5 & 49.9 \\
$\mathrm{Cu}_{15}$ MgAlO & 15.2 & 23.7 & 61.1 & 35.4 \\
$\mathrm{Cu}_{20}$ MgAlO & 14.1 & 18.4 & 67.5 & 27.9 \\
\hline
\end{tabular}
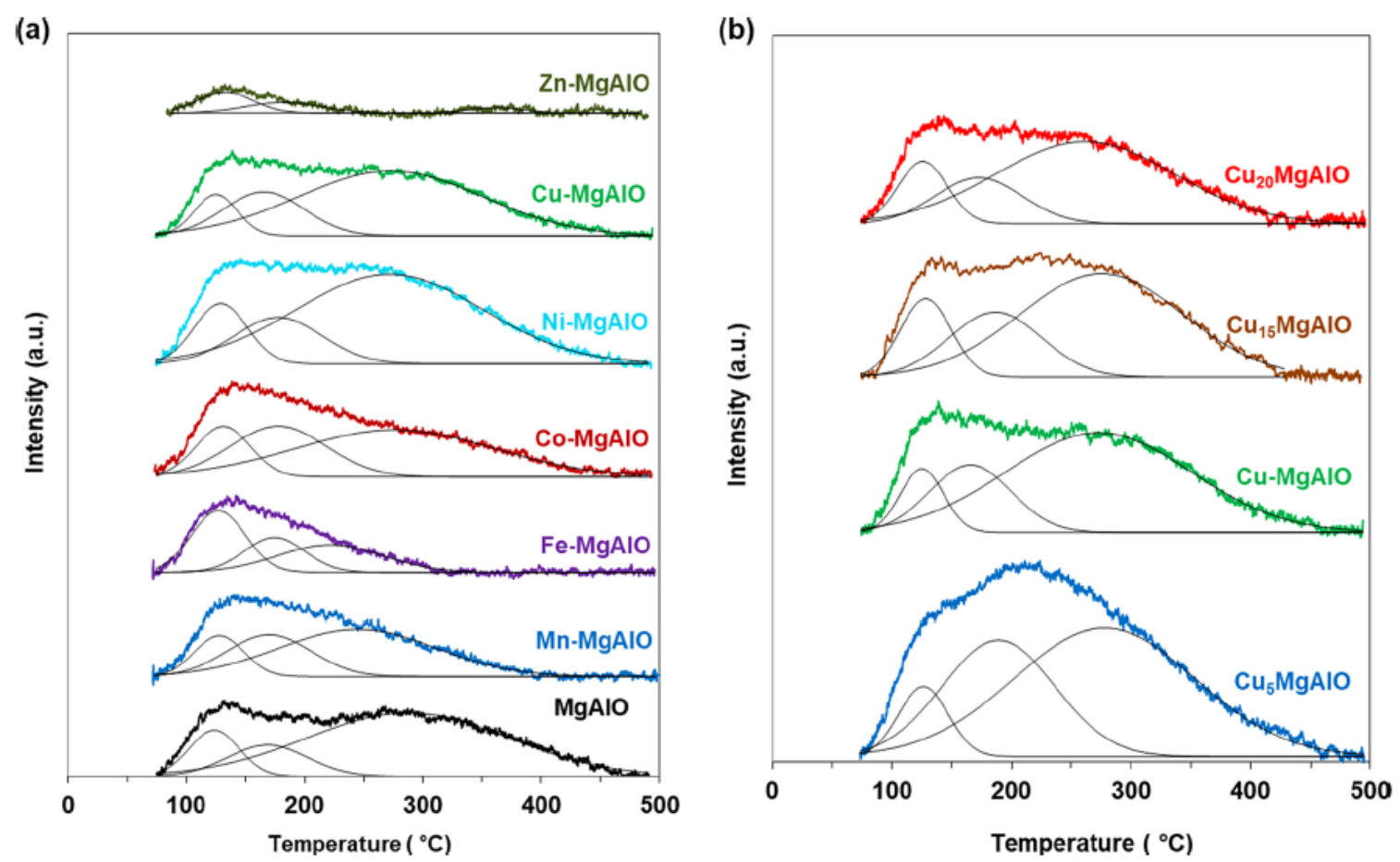

Fig. 6. $\mathrm{CO}_{2}$-TPD profiles of the (a) M-MgAlO and (b) CuxMgAlO mixed oxide catalysts.

Except for the Zn-MgAlO mixed oxide, all the other samples exhibited mainly strong and medium basic sites. Introduction of transition-metal cations in the MgAlO structure decreased the total number of sites for the $\mathrm{Zn-}$, Fe- and Mn-containing solids (Table 4), while increasing it for the $\mathrm{Ni}-\mathrm{MgAlO}$ and Cu-MgAlO mixed oxides. For the CuxMgAlO mixed 
oxides the total amount of basic sites decreased with increasing the $\mathrm{Cu}$ content. In our study, no correlation was observed between the basicity of the samples and the electronegativity of the transition metal cation M.

\subsection{Catalytic tests}

The catalytic results for the HDO of benzyl alcohol on the M-MgAlO mixed oxides containing 10 at. \% transition metal are presented in Table 5 . It can be observed that the catalytic performance strongly depends on the nature of the transition-metal cation, the CuMgAlO sample showing the best results in terms of both alcohol conversion (87.5\%) and toluene selectivity (83.4\%). All other catalysts show only very low conversion of ca. $10 \%$ or lower.

The four main products observed on the M-MgAlO catalysts were toluene, benzaldehyde, benzyl benzoate and benzene respectively, the selectivities decreasing in this order for most of catalysts. Exceptions are Fe- and Zn-containing catalysts showing higher selectivities for benzaldehyde than toluene and MgAlO sample having high selectivity for benzyl benzoate similar with the results for the test without catalyst. For the Mn-MgAlO sample the selectivity for benzaldehyde is only slightly lower than that for toluene.

Table 5 Conversion and selectivity values for the HDO of benzyl alcohol on M-MgAlO mixed oxides ( $50 \mathrm{mg}$ catalyst, $230 \circ \mathrm{C}, 5 \mathrm{~atm} \mathrm{H} 2,3 \mathrm{~h}$ reaction time).

\begin{tabular}{|c|c|c|c|c|c|}
\hline \multirow[b]{2}{*}{ Catalyst } & \multirow{2}{*}{$\begin{array}{l}\text { Benzyl } \\
\text { alcohol } \\
\text { conversion } \\
(\%)\end{array}$} & \multicolumn{4}{|c|}{ Selectivity (\%) } \\
\hline & & Toluene & Benzaldehyde & $\begin{array}{l}\text { Benzyl } \\
\text { benzoate }\end{array}$ & Benzene \\
\hline $\begin{array}{l}\text { No } \\
\text { catalyst }\end{array}$ & 1.1 & 0.0 & 34.4 & 65.6 & 0.0 \\
\hline MgAlO & 10.9 & 0.0 & 25.6 & 64.3 & 10.2 \\
\hline MnMgAlO & 1.8 & 47.6 & 42.7 & 9.7 & 0.0 \\
\hline Fe-MgAlO & 3.5 & 37.0 & 63.0 & 0.0 & 0.0 \\
\hline Co-MgAlO & 5.4 & 71.9 & 26.2 & 1.8 & 0.1 \\
\hline Ni-MgAlO & 10.6 & 79.5 & 19.1 & 0.5 & 0.9 \\
\hline $\begin{array}{l}\mathrm{Cu}^{-} \\
\text {MgAlO }\end{array}$ & 87.5 & 83.4 & 12.5 & 3.2 & 0.9 \\
\hline Zn-MgAlO & 2.6 & 1.8 & 77.9 & 20.3 & 0.0 \\
\hline
\end{tabular}


The presence of benzaldehyde among the reaction products can be explained by the dissociative adsorption of benzyl alcohol on the surface basic $\left(\mathrm{O}^{2-}\right.$ ions) and acidic sites (metal ions), leading to the formation of a metal benzylate intermediate, $\mathrm{C} 6 \mathrm{H} 5-\mathrm{CH}_{2}-\mathrm{O}-\mathrm{M}$, where $\mathrm{M}$ is a metal atom on the catalyst surface [43]. Benzaldehyde is then formed through a hydride ion abstraction.

Benzaldehyde is then formed through a hydride ion abstraction. Toluene is formed by the hydrogenolysis of the $\mathrm{C}-\mathrm{O}$ bond in benzyl alcohol, as previously showed $[2,26,29,30]$. The formation of benzyl benzoate by the disproportionation of benzaldehyde was also observed by Tanabe et al. [43] over alkaline earth metal oxides, in inert atmosphere at medium temperatures (up to $200 \circ \mathrm{C}$ ). The catalytic activity was correlated with the basicity of the oxides $\left(\mathrm{BaO} \geq \_\mathrm{SrO} \geq \_\mathrm{CaO}>\mathrm{MgO} \geq \mathrm{BeO}\right)$ and the authors concluded that the active sites were both basic (O2? _ions) and acidic (Lewis acid, metal ions). The active species seemed to be the metal benzylate intermediates formed on the surface of the catalysts, and their existence was proved by IR studies. The isotopic studies showed that the heterogeneous reaction mechanism is similar with the homogeneous Canizzaro and Tishchenko mechanisms, but with different activation energy and reaction order of benzaldehyde [43]. 


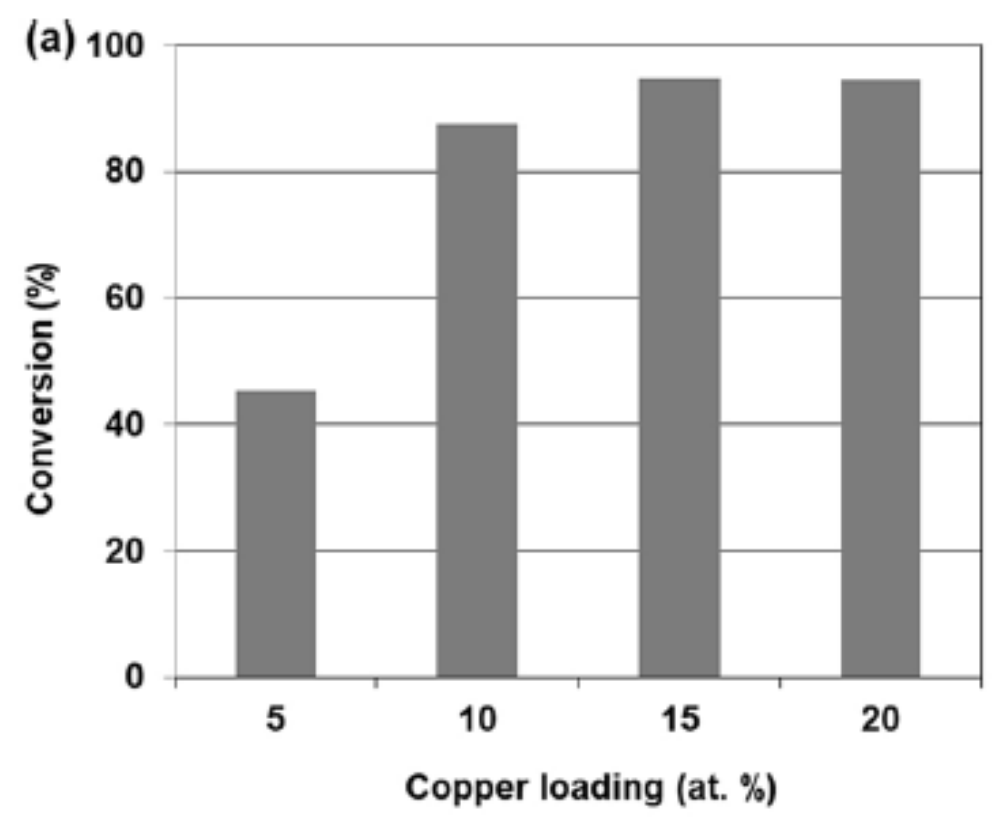

(b)

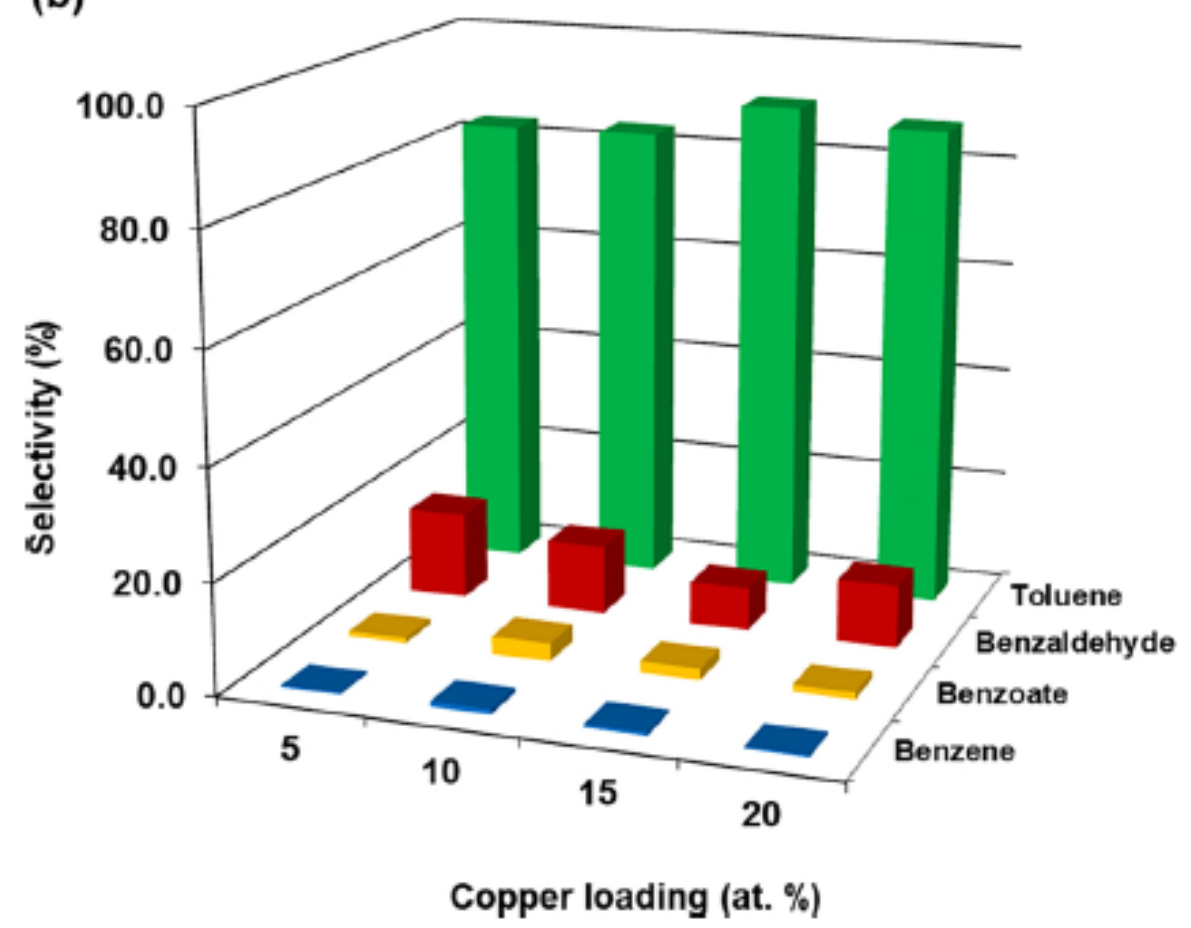

Fig. 7. (a) Conversion and (b) selectivity values for the HDO of benzyl alcohol on CuxMgAlO catalysts ( $50 \mathrm{mg}$ catalyst, $230 \circ \mathrm{C}, 5 \mathrm{~atm} \mathrm{H} 2,3 \mathrm{~h}$ reaction time).

Since the Cu-containing mixed oxide were showing the best performance in HDO reaction of benzyl alcohol among the M-MgAlO catalysts studied, the variation of $\mathrm{Cu}$ loading was investigated in the range 5-20 at \%. The results of the $\mathrm{Cu}$ loading variation are presented in Fig. 7. The alcohol conversion increased with increasing the copper loading up to 15 at \%, 
then it remained constant at ca. $95 \%$ (Fig. 7a). All Cu-containing catalysts gave toluene as the main product, with selectivities higher than $80 \%$ (Fig. 7b). With the Cu15MgAlO catalyst a selectivity to toluene of ca. $90 \%$, corresponding to a yield of ca. $85 \%$, was obtained. Benzaldehyde was obtained with less than $15 \%$ selectivity that diminished with increasing Cu loading, while benzene and benzyl benzoate were produced in very low amounts.

Notably, the reaction rate (in mol gcat-1 h-1) increases with the hydrogen consumption in H2-TPR measurements up to the sample with $15 \% \mathrm{Cu}$ (Cu15MgAlO) and then remains constant for the Cu20MgAlO catalyst (Fig. 8). This clearly suggests that the surface reducible copper species are involved in the catalytic activation of benzyl alcohol.

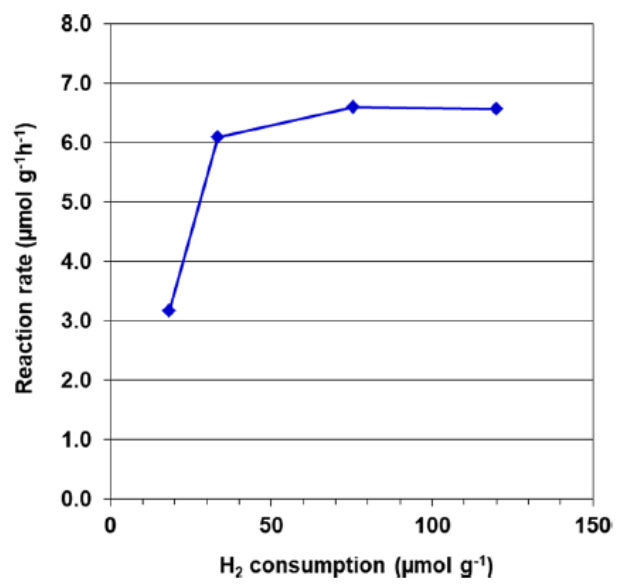

Fig. 8. Reaction rate ( $\mu$ mol gcat $-1 \mathrm{~h}-1$ ) on the CuxMgAlO catalysts vs. the $\mathrm{H} 2$ consumption ( $\mu$ mol g-1) in the H2-TPR experiments.

The influence of the reaction temperature on the HDO reaction of benzyl alcohol was investigated on the Cu15MgAlO catalyst in the $150-230{ }^{\circ} \mathrm{C}$ range. The results are shown in Fig. 9. Benzyl alcohol conversion increases exponentially with temperature in the range from 150 to $200{ }^{\circ} \mathrm{C}$. Then, likely due to diffusional limitations, it increases slowly, reaching $88.5 \%$ at $230{ }^{\circ} \mathrm{C}$. Toluene is the main product obtained within the whole range of temperature, with selectivities higher than $80 \%$ (Fig. 9b). Benzaldehyde was also obtained but with a selectivity well below $20 \%$, while benzene and benzyl benzoate were formed in very low 
amounts even at high temperatures. Methanol was never observed among the reaction products suggesting that benzene is not formed by the hydrogenolysis of the $\mathrm{C}-\mathrm{C}$ bond between the aromatic ring and $-\mathrm{CH} 2 \mathrm{OH}$ group, but rather by toluene dealkylation. Notably, toluene was also observed to be the main product in the HDO of benzyl alcohol on a CuCr2O4 catalyst in the same temperature range [3]. Since the toluene yield was maximum at $230 \circ$ C, i.e. $77 \%$, all the following tests were performed at this temperature.
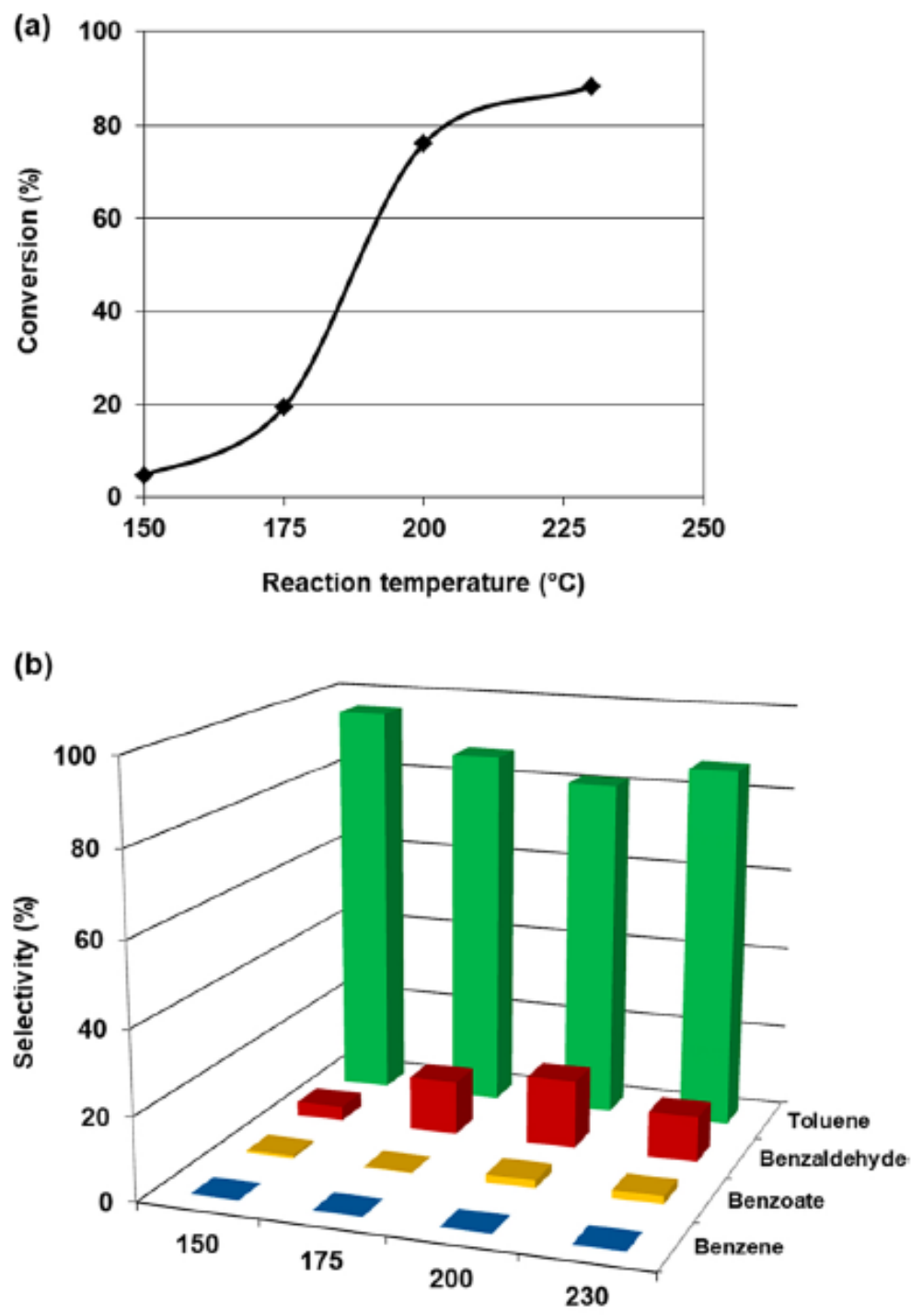

Reaction temperature $\left({ }^{\circ} \mathrm{C}\right)$

Fig. 9. Influence of the reaction temperature on (a) conversion and (b) product selectivities in the HDO of benzyl alcohol on Cu15MgAlO catalyst ( $50 \mathrm{mg}$ catalyst, 5 atm $\mathrm{H} 2,1 \mathrm{~h}$ reaction time). 

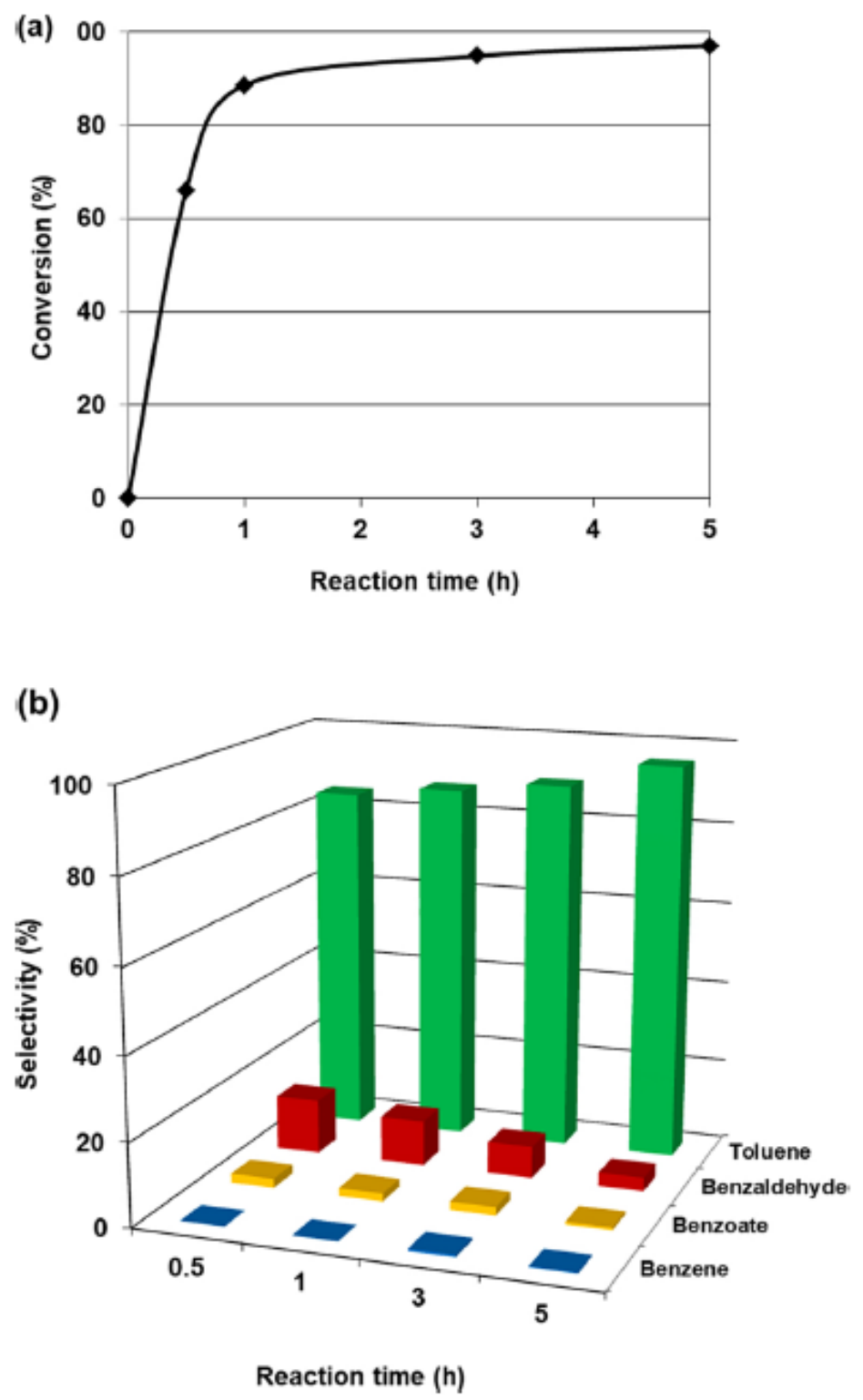

Fig. 10. Effect of reaction time on (a) alcohol conversion and (b) product selectivities in the $\mathrm{HDO}$ of benzyl alcohol on Cu15MgAlO catalyst ( $50 \mathrm{mg}$ catalyst, $230{ }^{\circ} \mathrm{C}, 5 \mathrm{~atm} \mathrm{H}$ )

The influence of the reaction time was investigated for the Cu15MgAlO catalyst in the range from 30 min to $5 \mathrm{~h}$, and the alcohol conversion (Fig. 10a) increased according to a typical curve for a batch-type reactor, up to $97 \%$. The selectivity to toluene, which is the main reaction product, increased with reaction time from $84 \%$ at $30 \mathrm{~min}$ to ca. $96 \%$ after $5 \mathrm{~h}$ (Fig. 10b). The selectivities for benzene and benzyl benzoate remained very small, while that for benzaldehyde showed an important decrease, from ca. $13 \%$ at $30 \mathrm{~min}$ to ca. $3 \%$ at $5 \mathrm{~h}$ 
reaction time. Since after $1 \mathrm{~h}$ the alcohol conversion reached ca. $90 \%$, the following catalytic tests were performed for this duration. These results suggest that benzaldehyde is a reaction intermediate, being further converted into toluene at higher reaction times. This is in agreement with the studies of Prochazkova et al. [14] on the hydrodeoxygenation of benzaldehyde to benzyl alcohol and toluene over supported Pd catalysts, in which the authors observed that the $\mathrm{C}=\mathrm{O}$ bond hydrogenation to alcohol followed by hydrogenolysis is the main pathway when the support was acidic (zeolites); while for Pd/C the direct hydrogenolysis of the carbonyl group leading to toluene was equally important. In a similar study, Gonzalez et al. [15] also found benzaldehyde to be an intermediate in benzyl alcohol HDO on Pt and Pd supported on Al2O3. In our study, in the HDO test of benzaldehyde on the Cu15MgAlO catalyst in identical reaction conditions, benzaldehyde was transformed with 38 \% conversion to the same compounds as benzyl alcohol: toluene ( $31 \%$ selectivity), benzyl alcohol (27\%), benzene ( $2 \%)$ and benzyl benzoate (40 \%). Benzoic acid was not observed in the reaction mixture. These findings confirm the hypothesis that benzaldehyde is formed as a reaction intermediate during the early stages of the reaction, when the $\mathrm{Cu}-\mathrm{MgAlO}$ catalyst is reduced. Catalytic tests in the same reaction conditions but using an aliphatic alcohol with the same number of carbon atoms, 1-heptanol, resulted in lower conversions, i.e. 11.6 and $46.6 \%$ after 5 and $24 \mathrm{~h}$ reaction times, respectively. The selectivities for HDO products (mainly hexane and heptane) were quite low, i.e. 5.2 and $8.4 \%$, respectively, while the main products were heptyl heptanoate and heptanal. These results suggest that the reaction pathway is similar for both benzyl alcohol and 1-heptanol, but either higher temperatures or higher hydrogen pressure are needed to activate the aliphatic alcohol on the Cu15MgAlO catalyst and to further convert the aldehyde intermediate into hydrocarbon. 

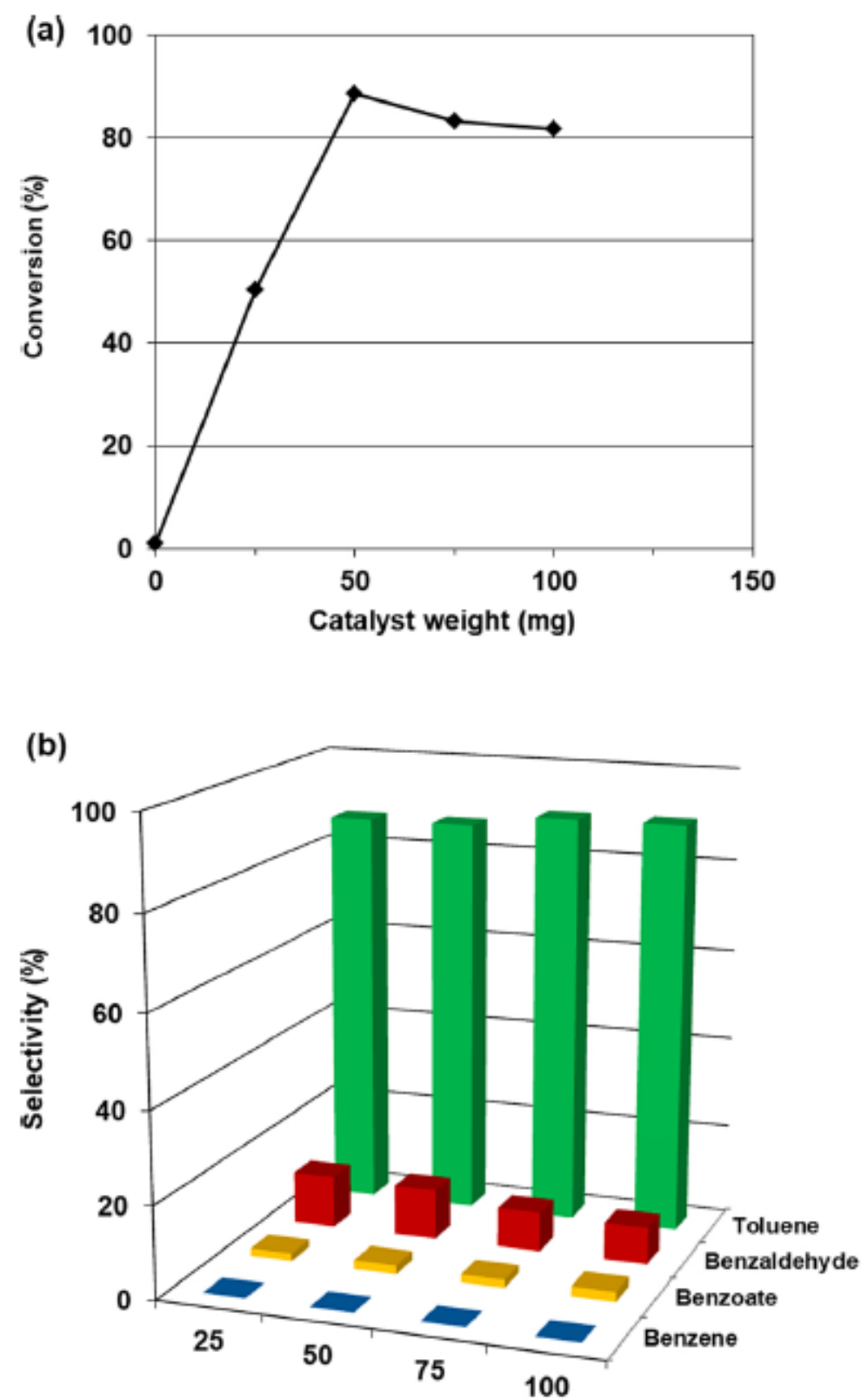

Catalyst weight (mg)

Fig. 11. Influence of the amount of catalyst on (a) conversion and (b) product selectivities in the HDO of benzyl alcohol on Cu15MgAlO ( $230 \circ \mathrm{C}, 5 \mathrm{~atm} \mathrm{H2}, 1 \mathrm{~h}$ reaction time).

The effect of the catalyst weight was investigated in the range 25-100 mg, the optimum weight found being $50 \mathrm{mg}$ (Fig. 11). In the absence of catalyst, the conversion was of only 1 $\%$. At catalyst weights higher than $50 \mathrm{mg}$ the conversion slightly decreased, possibly due to mixing problems in the three-phase system as already observed in other cases [44-46]. The 
products selectivity was found to be only little influenced by the catalyst weight (Fig. 11b). We can note that in the absence of catalyst, benzyl alcohol was only converted to toluene (65.6\%) and benzaldehyde (34.4\%).

Cu15MgAlO sample is reported in Table 6 . The reduction was performed at $230{ }^{\circ} \mathrm{C}$ for $1 \mathrm{~h}$ (the same as the reaction conditions) in hydrogen flow (20 $\mathrm{ml} \mathrm{min-1)}$ and the reduced catalyst $(50 \mathrm{mg}$ ) was immediately placed in the autoclave together with the benzyl alcohol, purged with hydrogen, then the $\mathrm{H} 2$ pressure was increased to $5 \mathrm{~atm}$ and the heating was started. Lower alcohol conversion and also lower selectivity for toluene were obtained with the pre-reduced catalyst. This indicates that the in-situ reduction of the catalyst, leading to Cu2O phase (Fig. 3), is more favorable and that a reduction pre-treatment is not necessary. Probably the pre-treatment leads to a deeper reduction of the copper active phase that is not beneficial to the hydrodeoxygenation process.

Table 6 Influence of the reduction pre-treatment on the conversion and selectivities for products in the HDO of benzyl alcohol on Cu15MgAlO ( $230{ }^{\circ} \mathrm{C}, 50 \mathrm{mg}$ catalyst, $5 \mathrm{~atm} \mathrm{H} 2,1 \mathrm{~h}$ reaction time).

\begin{tabular}{|c|c|c|c|c|c|}
\hline \multirow[b]{2}{*}{$\begin{array}{l}\mathrm{Cu}_{15} \mathrm{MgAlO} \\
\text { catalyst }\end{array}$} & \multirow{2}{*}{$\begin{array}{l}\text { Benzyl } \\
\text { alcohol } \\
\text { conversion } \\
(\%)\end{array}$} & \multicolumn{4}{|c|}{ Selectivity (\%) } \\
\hline & & Toluene & Benzaldehyde & $\begin{array}{l}\text { Benzyl } \\
\text { benzoate }\end{array}$ & Benzene \\
\hline calcined & 88.5 & 87.0 & 11.0 & 1.9 & 0.1 \\
\hline pre-reduced & 77.4 & 70.3 & 12.2 & 17.2 & 0.4 \\
\hline
\end{tabular}

\section{Conclusions}

The performance of the LDH-derived MMgAlO catalysts in the HDO reaction of benzyl alcohol strongly depends on the nature of the transition-metal $\mathrm{M}$ and its content. Also, the reaction conditions, including temperature, reaction time, catalyst weight, influence both the alcohol conversion and product selectivities. The best catalyst, Cu15MgAlO, showed 
high alcohol conversion (97\%) and high selectivity to toluene (96\%) in optimum reaction conditions. A correlation was found between the reaction rate and the $\mathrm{H} 2$ consumption in H2-TPR experiments for the CuxMgAlO mixed oxides suggesting that surface reducible copper species are involved in catalysis, while no correlation could be established with the basicity of the catalysts. The catalytic performance of the Cu15MgAlO system in the HDO reaction of 1-heptanol in similar conditions was shown to be significantly lower.

\section{Acknowledgments}

The authors are grateful to Chem. Florentina Urlan, M. Sc., for performing the ICP-OES measurements.

\section{References}

[1] P.M. Mortensen, J.-D. Grunwaldt, P.A. Jensen, K.G. Knudsen, A.D. Jensen, Appl. Catal. A Gen. 407 (2011) 1-19.

[2] N.A. DeLucia, N. Das, S. Overa, A. Paul, A.K. Vannucci, Catal. Today 302 (2018) 146-150.

[3] K.L. Deutsch, B.H. Shanks, Appl. Catal. A Gen. 447-448 (2012) 144-150.

[4] V.A. Yakovlev, S.A. Khromova, O.V. Sherstyuk, V.O. Dundich, D.Yu. Ermakov, V. M. Novopashina, M.Yu. Lebedev, O. Bulavchenko, V.N. Parmon, Catal. Today 144 (2009) 362366.

[5] K.L. Luska, P. Migowski, S. El Sayed, W. Leitner, Angewandte Chemie (Int. Ed.) 54 (2015) 15750-15755.

[6] C. Zhao, Y. Kou, A.A. Lemonidou, X. Li, J.A. Lercher, Angewandte Chemie (Intl. Ed) 48 (2009) 3987-3990.

[7] Y.-K. Hong, D.-W. Lee, H.-J. Eom, K.-Y. Lee, Appl. Catal. B 150-151 (2014) 438-445. 
[8] M.V. Bykova, D.Yu. Ermakov, V.V. Kaichev, O.A. Bulavchenko, A.A. Saraev, M. Yu. Lebedev, V.A. Yakovlev, Appl. Catal. B 113-114 (2012) 296-307.

[9] P.M. Mortensen, J.-D. Grunwaldt, P.A. Jensen, A.D. Jensen, ACS Catal. 3 (2013) 17741785. [10] D.B. Larsen, A.R. Petersen, J.R. Dethlefsen, A. Teshome, P. Fristrup, Chem. Eur. J. 22 (2016) 16621-16631.

[11] C. Zhao, Y. Kou, A.A. Lemonidou, X. Li, J.A. Lercher, Chem. Commun. 46 (2010) 412-414.

[12] T. Cordero-Lanzac, R. Palos, I. Hita, J.M. Arandes, J. Rodríguez-Mirasol, T. Cordero, J. Bilbao, P. Casta no, Appl. Catal. B 239 (2018) 513-524.

[13] C.A. Teles, P.M. de Souza, A.H. Braga, R.C. Rabelo-Netoa, A. Teran, G. Jacobs, D. E. Resasco, F.B. Noronha, Appl. Catal. B 249 (2019) 292-305.

[14] D. Prochazkova, P. Zamostn., M. Bejblova, L. Cerven., J. Cejka, Appl. Catal. A Gen. 332 (2007) 56-64.

[15] C. Gonzalez, P. Marín, F.V. Díez, S. Ordoñez, Ind. Eng. Chem. Res. 55 (2016) 2319-2327. [16] L. Offner-Marko, A. Bordet, G. Moos, S. Tricard, S. Rengshausen, B. Chaudret, K. L. Luska, W. Leitner, Angewandte Chemie (Intl. Ed) 57 (2018) 12721-12726.

[17] I.T. Ghampson, C. Sepúlveda, R. Garcia, J.L. García Fierro, N. Escalona, W. J. DeSisto, Appl. Catal. A Gen. 435-436 (2012) 51-60.

[18] S. Leng, X. Wang, X. He, L. Liu, Y. Liu, X. Zhong, G. Zhuang, J. Wang, Catal. Commun. 41 (2013) 34-37.

[19] L. Nie, P.M. de Souza, F.B. Noronha, W. An, T. Sooknoi, D.E. Resasco, J. Mol. Catal. A Chem. 388-389 (2014) 47-55.

[20] Z. Wang, Y. Zeng, W. Lin, W. Song, Int. J. Hydrogen Energy 42 (2017) 21040-21047.

[21] X. Liu, W. An, C.H. Turner, D.E. Resasco, J. Catal. 359 (2018) 272-286. 
[22] E. Ochoa, D. Torres, R. Moreira, J.L. Pinilla, I. Suelves, Appl. Catal. B 239 (2018) 463-474.

[23] M. Lu, Y. Sun, P. Zhang, J. Zhu, M. Li, Y. Shan, J. Shen, C. Song, Ind. Eng. Chem. Res. 58 (2019) 1513-1524.

[24] P. Sangnikul, C. Phanpa, R. Xiao, H. Zhang, P. Reubroycharoen, P. Kuchonthara, T. Vitidsant, A. Pattiya, N. Hinchiranan, Appl. Catal. A Gen. 574 (2019) 151-160.

[25] R. Shi, F. Wang, X. Mu, Y. Li, X. Huang, W. Shen, Catal. Commun. 11 (2009) 306-309.

[26] M. Dixit, M. Mishra, P.A. Joshi, D.O. Shah, J. Ind. Eng. Chem. 19 (2013) 458-468.

[27] B. Dragoi, A. Ungureanu, A. Chirieac, C. Ciotonea, C. Rudolf, S. Royer, E. Dumitriu, Appl. Catal. A Gen. 504 (2015) 92-102.

[28] B. Pu'ertolas, T.C. Keller, S. Mitchell, J. P’erez-Ramírez, Appl. Catal. B 184 (2016) 77-86. [29] C.-H. Lien, J.W. Medlin, J. Phys. Chem. C 118 (2014) 23783-23789.

[30] C.-H. Lien, J.W. Medlin, J. Catal. 339 (2016) 38-46.

[31] S. Tanasoi, G. Mitran, N. Tanchoux, T. Cacciaguerra, F. Fajula, I. Sandulescu, D. Tichit, I.C. Marcu, Appl. Catal. A Gen. 395 (2011) 78-86.

[32] O.D. Pavel, D. Tichit, I.-C. Marcu, Appl. Clay Sci. 61 (2012) 52-58. [33] V. Rives, M.A. Ulibarri, Coord. Chem. Rev. 181 (1999) 61-120.

[34] I.-C. Marcu, D. Tichit, F. Fajula, N. Tanchoux, Catal. Today 147 (2009) 231-238.

[35] S. Tanasoi, N. Tanchoux, A. Urd`a, D. Tichit, I. Sandulescu, F. Fajula, I.-C. Marcu, Appl. Catal. A Gen. 363 (2009) 135-142.

[36] A.V. Neimark, K.S.W. Sing, M. Thommes, Surface Area and porosity, in: G. Ertl, H. Knozinger, F. Schuth, J. Weitkamp (Eds.), Handbook of Heterogeneous Catalysis, 2nd ed., Wiley-VCH, 2008, pp. 721-738.

[37] J.J. Bravo-Sua rez, B. Subramaniam, R.V. Chaudhari, J. Phys. Chem. C 116 (2012) 1820718221. 
[38] A. Corma, V. Fornes, M.R. Martin-Aranda, F. Rey, J. Catal. 134 (1992) 58-65.

[39] J.I. Di Cosimo, V.K. Diez, M. Xu, E. Iglesia, C.R. Apesteguia, J. Catal. 178 (1998) 499-510. [40] V.K. Diez, C.R. Apesteguia, J.I. Di Cosimo, Catal. Today 63 (2000) 53-62.

[41] F. Prinetto, G. Ghiotti, R. Durand, D. Tichit, J. Phys. Chem. B 104 (2000) 11117-11126.

[42] I.-C. Marcu, N. Tanchoux, F. Fajula, D. Tichit, Catal. Letters 143 (2013) 23-30.

[43] K. Tanabe, K. Saito, J. Catal. 35 (1974) 247-255. [44] W. Xie, H. Peng, L. Chen, J. Mol. Catal. A Chem. 246 (2006) 24-32.

[45] W. Xie, T. Wang, Fuel Process. Technol. 109 (2013) 150-155.

[46] H.-Y. Zeng, Z. Feng, X. Deng, Y.-Q. Li, Fuel 87 (2008) 3071-3076. 